\title{
In Utero and Lactational Exposure of F1 Adult Pups to Ethanol and Nicotine: Alteration of The Reproductive System and Epigenetic Modifying Enzymes of Sperm Cells?
}

\section{Athareh Pabarja \\ Neuroscience Research Center, Institute of Neuropharmachology, Kerman University of Medical \\ Sciences, Kerman, Iran}

\section{Sepideh Ganjalikhan Hakemi}

Department of anatomical sciences, School of medicine, Kerman University of Medical Sciences, Kerman, Iran.

\section{Elahe Musanejad}

Department of anatomical sciences, School of medicine, Kerman University of Medical Sciences, Kerman, Iran.

\section{Massood Ezzatabadipour}

Department of anatomical sciences, School of medicine, Kerman University of Medical Sciences, Kerman, Iran.

\section{Seyed Noreddin Nematollahi-Mahani}

Department of anatomical sciences, School of medicine, Kerman University of Medical Sciences, Kerman, Iran.

\section{Ali Afgar}

Research Center for Hydatid Disease in Iran, Kerman University of Medical Sciences, Kerman, Iran.

\section{Mohammad Reza Afarinesh}

Neuroscience Research Center, Institute of Neuropharmachology, Kerman University of Medical Sciences, Kerman, Iran

\section{Tahereh Haghpanah ( $\nabla$ thaghpanah1984@gmail.com )}

Department of anatomical sciences, School of medicine, Kerman University of Medical Sciences, Kerman, Iran.

\section{Research Article}

Keywords: nicotine, ethanol, F1 offspring, male reproductive system, epigenetics modifications, germline transmission

Posted Date: January 5th, 2021 
DOI: https://doi.org/10.21203/rs.3.rs-136010/v1

License: (c) (1) This work is licensed under a Creative Commons Attribution 4.0 International License. Read Full License 


\section{Abstract}

Co-use of alcohol and nicotine is a common habit which could affect reproductive system. The present study was designed to investigate the effect of in-utero and lactational exposure of offspring to alcohol, nicotine, and combinations on the reproductive system and epigenetic alterations of male gamete. Pregnant mice and lactating NMRI pups randomly received nicotine, ethanol, and combinations during gestational days 1 until weaning. Sperm and testes were collected on postnatal day 90 for further experiments. Exposure to these substances, particularly, nicotine, highly affected testicular Johnsen's score, sperm parameters including; number, motility, viability, DNA integrity and also serum MDA level. Interestingly, concurrent exposure to nicotine and alcohol somehow reversed the effects. Quantitative real-time PCR data showed an increase in the mRNA level of histone deacetylation 1 and 2 and a decrease in the level of DNA methyltransferase (DNMT) 3A, while no marked differences in the expression level of DNMT1 and 3B were observed between the exposed and non-exposed pups. Alleviating effects were observed in the epigenetic modifying enzymes transcripts of co-exposed pups compared with the exposure to nicotine or alcohol. Taken together, our findings determined that exposure of offspring inutero and during lactational period to these substances could result in lasting epigenetic changes in sperm cells. However, unexpectedly co-exposure of pups to nicotine and alcohol lessened these negative effects.

\section{Introduction}

Despite the well-known hazards and repeated warnings about smoking and alcohol drinking during pregnancy, some mothers still continue to use them. Considering rapid transmission of these substances through placental membrane ${ }^{1,2}$ and secretion in the milk ${ }^{3,4}$, a significant population yet face with these substances during in utero life and also in breastfeeding period.

Each puff of cigarette is a complex mixture of more than 1000 chemicals. Of them, nicotine, a very toxic alkaloid, is one of the well-established dangerous substances. Sometimes, nicotine replacement therapy (NRT) is recommended as an effective method for smoking cessation during pregnancy ${ }^{5}$. Although developing fetus to some extent is protected from exposure to various chemicals and carcinogens in the cigarette, however, nicotine exposure, by itself is a crucial issue which affects various body organs including reproductive system. Alcohol intake, especially at higher doses is also associated with symptoms such as growth retardation, facial dysfunction and brain damage ${ }^{6}$. A growing body of evidence, both in rodents and humans, suggests that maternal exposure to nicotine and alcohol during key times of the reproductive system development and germ cell formation could result in abnormalities in male reproductive system, embryonic gonadal germ cells ${ }^{7}$, hormonal status, sperm quality ${ }^{8-11}$, and subsequently may negatively affect fertility potential of adult offspring. Nevertheless, there are some contradictory reports ${ }^{12,13}$. Epidemiologic studies have shown that the simultaneous consumption of nicotine and alcohol is more common ${ }^{14,15}$. Approximately eighty percent of people who consume alcohol are smoker ${ }^{16}$. It is well-known that consumption of any of these substances increase desire for the other 
17 , so that the current smoking behavior of each person may predict alcohol dependence ${ }^{18}$. Several toxicologic studies focusing on the adverse effects of nicotine and alcohol and their combination, have been conducted so far, yet very few records have addressed the cumulative effects of in utero exposure to alcohol and nicotine on developing reproductive system of male offspring. A previous study has shown harmful effects of maternal exposure to nicotine, alone or concurrently with ethanol, during prenatal day 9-12 on embryo development, although this effect was spared in the ethanol-exposed embryos ${ }^{19}$.

Regardless of the well-established developmental toxicity of alcohol and nicotine on male offspring, their intrauterine programming mechanism is not well-studied. Exposure to environmental factors such as alcohol and nicotine during early life could induce modifications of specific genes expression without altering their sequence via aberrant epigenetic alterations in various tissues of offspring ${ }^{20-27}$. These alterations have permanent adverse developmental and functional effects. DNA methylation and histone modifications are one of the major mechanisms of epigenetic changes ${ }^{28}$. These modifications occur by activity of modificating enzymes including DNA methyltransferases (DNMTs) and histone acetylates (HAT) and deacetylases (HDACs) ${ }^{29}$. Several studies have evaluated the effects of maternal exposure to nicotine and alcohol, alone on a range of epigenetic changes in different tissues such as somatic and germ cells of male offspring ${ }^{24,26,29}$. Hypomethylation of placenta ${ }^{30}$, whole fetal genome ${ }^{31}$, and also imprinting genes such as $\mathrm{H} 19^{32}$ as well as decrease of DNMTs activity ${ }^{31}$ were reported.

Despite the co-use of alcohol and nicotine in the world's population is more common, the effect of concurrent exposure to these substances during embryofoetal and lactation periods on male offspring's reproductive system is not yet evaluated. Hence, in order to bring experimental evidences nearer to the actuality of human life, the main aim of the present study was to assess the sperm and testicular characteristics of offspring born from mothers whom received alcohol, nicotine and their combination during pregnancy and lactation periods. Moreover, we further evaluated whether such alterations could affect the expression level of the epigenetic modification enzymes in sperm of offspring.

\section{Methods}

\section{Animals}

A total of 25 adult NMRI mice ( 15 females and 10 male) aged 8-10 weeks and weighting 25-30 g were used for breeding. These animals were obtained from animal house of Afzalipour faculty of Medicine, Kerman. They were housed in polypropylene cages and were kept under standard condition of animal house with a temperature of $23+2^{\circ} \mathrm{C}$ and constant 12-hours light/dark cycle with free access to drinking water and standard pellet food.

\section{Experiment design}

Three female and one male mice (proportion of three females per male) were housed in one cage overnight and the vaginal plug was checked in the following morning. Presence of a vaginal plug was 
considered as gestational day (GD) 1. The pregnant mice were randomly allocated into 5 groups $(n=8)$ and treated daily as follows:

Vehicle group (Veh): the pregnant animals daily received $0.3 \mathrm{ml}$ normal saline by intraperitoneal (i.p.) injection.

Nicotine group (Nic): the pregnant mice daily received nicotine tartrate $\left(1 \mathrm{mg} / \mathrm{kg}\right.$, i.p., free base) ${ }^{8213}$.

Ethanol group (Ethn): the pregnant mice daily received ethanol (3 gr/ $\mathrm{kg}$, i.p.) ${ }^{53}$.

Nicotine + Ethanol group (Nic+Ethn): the pregnant mice daily received the same doses of nicotine and ethanol, simultaneously ${ }^{68}$.

Treatments started from GD1, continued throughout the pregnancy and lactation periods until offspring weaning (postnatal day; PND 21). The male offspring were maintained in separate cages under the same controlled conditions until PND 90. In order to prevent from any gene homogeneity, only 2 male offspring of each dam were randomly assigned for each experimental group $(n=8)$.

\section{Blood collection}

At PND 90, 8 pups of each group were anesthetized using ketamine $((5-10 \mathrm{mg} / \mathrm{kg}) /$ xylazine $(5 \mathrm{mg} / \mathrm{kg})$, and their blood was collected from left ventricle. Blood samples were centrifuged at 2500-3000 rpm for 10 minutes and the serum removed and held at $-20^{\circ} \mathrm{C}$ for further evaluations.

\section{Testis and sperm collection}

The anesthetized animals were authonized by cervical dislocation, their abdomen wall was cut and the left cauda epididymis of each mice were carefully removed, and were transferred into a petri dish containing $1 \mathrm{~mL}$ pre-warmed HTF media supplemented by $15 \mathrm{mg} / \mathrm{mL}$ bovine serum albumin. It was cut by a pair of scissors, to release sperm cells. The petri dishes were incubated at $370 \mathrm{C}$ for 15 minutes. Meantime, the left testes were removed and weighted by a digital scale. Testes dimensions including length, width and thickness, were measured using a standard digital caliper and then fixed by dipping in Bouin's solution for 48 hours.

\section{Sperm parameters analysis}

\section{Sperm motility}

After incubation of sperm cells for 15 minutes, the suspension was collected, quietly pipetted, $10 \mu \mathrm{L}$ of sperm suspension was deposed on the pre-warmed slide, covered by coverslip and then the motility of at least 200 sperm cells was evaluated under a light microscope at $\times 200$ magnification in 10 random fields. The motility rate was expressed as the number of motile sperm cells to total counted sperm cells $(\times 100$ 83. 


\section{Sperm number}

Five $\mu \mathrm{L}$ of sperm suspension was mixed with $5 \mu \mathrm{L}$ of sperm fixative solution (formalin/sodium bicarbonate). The mixture was pipetted and the solution was placed on an improved Neubauer hemocytometer and the sperm heads were counted under a light microscope (Olympus BX 51, Tokyo, Japan) at $\times 200$ magnification. The sperm number was expressed as million per one $\mathrm{mL}$ of suspension 84.

\section{Sperm viability}

Ten $\mu \mathrm{L}$ of sperm suspension was mixed with an equal volume of $1 \%$ eosin $\mathrm{Y} / 5 \%$ nigrosin staining solution in a microtube. After 2 minutes, a smear was prepared, air dried and at least 200 sperm cells were evaluated at $\times 1000$ magnification under immersion oil. (Figure 2-D). The sperm viability rate was calculated as the number of unstained sperm cells (alive) to total counted sperm cells (white + red) $\times 100$ 85 .

The sperm parameters were evaluated by an expert operator blinded to experimental groups.

\section{Sperm DNA fragmentation assessment}

Sperm DNA fragmentation (SDF) was assessed by sperm chromatin dispersion (SCD) test based on our previous study with some changes ${ }^{86,87}$. Briefly, $30 \mu \mathrm{L}$ sperm suspension was mixed with $70 \mu \mathrm{L} 1 \%$ low gelling agarose, placed on a pre-coated slide with standard agarose $(0.65 \%)$, covered by coverslip and transferred to refrigerator $\left(4^{\circ} \mathrm{C}\right)$ to solidify. After 5 minutes, the coverslip was carefully removed and the slide was suspended in $0.08 \mathrm{~N} \mathrm{HCl}$ solution for 17 minutes at room temperature in darkness. Next, the slide was incubated in two consecutive lysis buffer solutions; lysis buffer solution 1 containing $0.4 \mathrm{M}$ Tris, $0.8 \mathrm{M}$ 2-mercaptoethanol, 1\% SDS and $50 \mathrm{mM}$ EDTA (pH 7.5) for 20 minutes followed by lysis buffer solution 2 containing $0.4 \mathrm{M}$ Tris, $2 \mathrm{M} \mathrm{NaCl}$ and 1\% SDS, ( $\mathrm{pH} 7.5)$ for 15 minutes. The slide was finally incubated in Trisborate-EDTA buffer (0.09 M Trisborate and $0.002 \mathrm{M}$ EDTA (pH 7.5) for 12 minutes. The slide was washed and dehydrated in increasing concentration of alcohol in water. The slide was stained by Diff-Quick solution for 3 minutes and air dried. Under light microscopy at $\times 400$ magnification, 300 sperm cells were scored based on their halo size; big and medium-sized halo indicate sperm cells without DNA fragmentation, while small-sized halo and also sperm with no halo indicate sperm cells with DNA fragmentation. SDF rate was calculated as the number of sperm cells with small and no halo to total number of counted sperm $\times 100^{88}$.

\section{Testicular morphometric evaluation}

The fixed testes were embedded in paraffin and sectioned by a rotary microtome (Leitz, Germany). Eight $5-\mu \mathrm{m}$ thick sections of middle part of each testis was prepared at 10- $\mu \mathrm{m}$ intervals. The sections were stained by hematoxylin/eosin, the diameter and the area of 10 round seminiferous tubules in each section were evaluated. In order to evaluate the quality of spermatogenesis and maturity of germinal 
epithelium, Johnsen's score was used as a semi-quantitative method in 80 seminiferous tubules per animal ${ }^{89}$. The scores were summed up and their means were reported as Johnsen's score (JS). All morphometric assessment of testicular tissue was performed in a blind fashion by an expert operator.

\section{Malondialdehyde (MDA) determination}

MDA level as a final product of lipid peroxidation in the serum of exposed pups (seven mice/ group) was assessed by thiobarbituric acid method using Nalondi ${ }^{\mathrm{TM}}$-Lipid Peroxidation Assay Kit-MDA

(Navandsalamat Company, Urimia, Iran) based on the manufacture instructions. In short, $200 \mu \mathrm{L}$ of serum was mixed with $1000 \mu \mathrm{L}$ of working solution containing 2-thiobarbituric acid and trichloroacetic acid and then incubated at $95^{\circ} \mathrm{C}$ for 45 minutes. The mixture was transferred on ice, incubated for 10 minutes and then, centrifuged at $1500 \mathrm{rpm}$ for 15 minutes. Absorbance of the supernatant was read at $532 \mathrm{~nm}$ by a spectrophotometer (Alpha-1860, Thomas Scientific, USA). MDA concentration was expressed as $\mathrm{nM} / \mathrm{mL}$.

\section{Total RNA extraction and complementary DNA synthesis}

Total RNA was extracted from sperm cells by RNX plus solution (Cinnagen, Iran) based on the manufacturer's instructions. In short, $1 \mathrm{~mL}$ of cold RNX plus solution was added to $1 \mathrm{~mL}$ of sperm suspension, and incubated at room temperature for 5 minutes. Then, $200 \mu \mathrm{L}$ of cold chloroform solution was added, shacked vigorously and centrifuged at $12000 \mathrm{rpm}$, at $4{ }^{\circ} \mathrm{C}$, for 15 minutes. The supernatant was transferred into a clean microtube, equal volume of cold isopropanol solution was added and the microtube was transferred to a $-20^{\circ} \mathrm{C}$ freezer, overnight. Next day, the mixture was centrifuged at 12000 $\mathrm{rpm}$, at $4{ }^{\circ} \mathrm{C}$ for 15 minutes. The upper phase was then removed, the pellet was washed by $75 \%$ ethanol, and again centrifuged at $12000 \mathrm{rpm}$, at $4{ }^{\circ} \mathrm{C}$, for 15 minutes. In the next stage, the supernatant was removed and the pellet was placed under a laminar- air flow hood to dryness. The dried pellet was resuspended in $20 \mu \mathrm{L}$ diethyl pyrocarbonate (DEPC)- treated water. The integrity and quantity of total RNA were verified by $1 \%$ agarose gel electrophoresis and the absorbance ratio at $260 / 280 \mathrm{~nm}$ with a NanoDrop 1000 spectrophotometer (Thermo Fisher Scientific, Wilmington, DE, United States), respectively. One $\mu \mathrm{g}$ of total RNA was converted into complementary DNA (cDNA) with $1 \mu \mathrm{L}$ of $200 \mathrm{U} / \mu \mathrm{L}$ SuperScript III Moloney Murine Leukemia Virus (M-MLV) reverse transcriptase (Fermentas, Burlington, Canada), Four $\mu \mathrm{L}$ of $5 \mathrm{X}$ first-strand buffer, $0.5 \mu \mathrm{L}$ of $40 \mathrm{U} / \mu \mathrm{L}$ RNase inhibitor, $1 \mu \mathrm{L}$ oligo (dT) primer and 1 $\mu \mathrm{L} 10 \mathrm{mM}$ dNTP were mixed in a $20 \mu \mathrm{L}$ reaction. The samples were incubated at $42{ }^{\circ} \mathrm{C}$ for 60 minutes, then the enzyme was deactivated at $70^{\circ} \mathrm{C}$ for 10 minutes using a thermocycler (Biometra, Germany) ${ }^{90}$. The specific primers were designed by the primer3 program. The primer sequences are presented in Supplementary table S1. Conventional reverse transcriptase (RT)-PCR was done for optimizing annealing temperature for each primer set. The RT-PCR products were evaluated by agarose gel electrophoresis $(2 \%)$.

\section{Quantitative real time PCR (qRT-PCR)}

Relative mRNA levels were quantified by real-time PCR with SYBR Green Master Mix 
(Genaxxon bioscience, Ulm, Germany) using a Light Cycler Real-Time PCR System (MIC (Queensland, Australia) for the following genes: DNMT1, DNMT3A and DNMT3B, HDAC1 and HDAC2. Beta actin was used as the housekeeping gene to normalize the qRT-PCR reaction. For the amplification reaction, $1 \mu \mathrm{L}$ synthetized cDNA solution was mixed with a $1 \mu \mathrm{L}$ specific primer and $10 \mu \mathrm{L}$ SYBR Green I Master in a 20 $\mu \mathrm{L}$ reaction. The thermocycler cycling conditions was as follows: $95^{\circ} \mathrm{C}$ for 15 minutes ( 1 rep), followed by 40 cycles of $95^{\circ} \mathrm{C}$ for 15 seconds, $60-62^{\circ} \mathrm{C}$ for 60 seconds and $72^{\circ} \mathrm{C}$ for 30 seconds. Melting curves were checked for the validation of amplification of a single PCR product. The $2^{-\Delta \Delta}$ cycle threshold method was used to assess gene expression levels.

\section{Statistical analysis}

Data analysis was conducted by using SPSS software (version 22). At first, data was analyzed for normality by using Kolmogorov-Smirnov test. Differences in parametric data were determined by One-way analysis of variance (ANOVA) test followed by Tukey post hoc test, while differences in non-parametric data were determined by using Kruskall-Wallis test. The data were presented as Mean \pm SEM. The Graphpad Prism software was used for graphing.

\section{Study Approval}

Animal research was approved by the Animal Experiment Committee of the Kerman University of Medical Sciences of Iran (approval no.: EC/97-10/KNRC) and confirming that all animal study methods were conducted in strict accordance with the relevant guidelines and regulations. All experimental procedures were carried out in accordance with the ARRIVE guidelines.

\section{Data Availability}

All data generated or analyzed during this study are included in this published article (and its Supplementary Information file).

\section{Results}

\section{Biometric analysis: testis weight and dimension}

The values of offspring's testes parameters are shown in Table 1. Exposure to nicotine and ethanol, either alone or in combination, during pregnancy and breastfeeding periods had no marked effects on testis weight, length, width and diameter in comparison to the unexposed vehicle group.

Table 1. The effects of exposure to nicotine and ethanol, either alone or simultaneously, during in utero life and breastfeeding periods on testicular weight and dimensions. 


\begin{tabular}{|lllll|}
\hline Groups & Testis weight $(\mathrm{gr})$ & Testis length $(\mathrm{mm})$ & Testis width $(\mathrm{mm})$ & Testis diameter $(\mathrm{mm})$ \\
\hline Vehicle & $0.11 \pm 0.12$ & $6.99 \pm 0.15$ & $4.65 \pm 0.74$ & $4.55 \pm 0.11$ \\
\hline Nicotine & $0.11 \pm 0.01$ & $7.62 \pm 0.24$ & $5.05 \pm 0.12$ & $5.02 \pm 0.12$ \\
\hline Ethanol & $0.11 \pm 0.01$ & $7.06 \pm 1.28$ & $4.96 \pm 0.71$ & $4.56 \pm 0.12$ \\
\hline Nic+Ethn & $0.11 \pm 0.00$ & $7.13 \pm 0.12$ & $4.71 \pm 0.95$ & $4.60 \pm 0.12$ \\
\hline
\end{tabular}

\section{Morphometric analysis of seminiferous tubules diameter and area}

Histopathological observations of testicular sections of unexposed animals in the vehicle group (Fig. 1-a) showed a typical architecture of seminiferous tubules with clear lumens and active spermatogenesis. However, the seminiferous tubules of nicotine-exposed mice (Fig. 1-b-e) revealed severe destructions such as atrophy, vacuoles and sloughing germinal epithelium with a small volume of sperm cells in the lumen. Also, in the ethanol (Fig. 1-f) and concurrent - exposed animals (Fig. 1-g), a perfect spermatogenesis event was observed in almost all the tubules, however several vacuoles were observed and yet sperm cells in the lumen were less than the unexposed mice.

Analysis of seminiferous tubules diameter revealed that this parameter was decreased in the Nic (68.28 \pm 1.74), Ethn (68.87 \pm 1.60$)$ and Nic+Ethn groups $(72.45 \pm 1.56)$ compared to those of the Veh group (77.09 \pm 0.80 ); nevertheless, the differences were not statistically significant (Table 2).

Table 2. The effects of exposure to nicotine and ethanol, either alone or simultaneously, during in utero life and breastfeeding periods on the averages of Johnsen's score and seminiferous tubules diameter and area in the testicular tissue of F1 adult pups.

\begin{tabular}{|llll|}
\hline Groups & Seminiferous tubule diameter $(\mu \mathrm{m})$ & Seminiferous tubule area $(\mu \mathrm{m})^{2}$ & Johnsen's score \\
\hline Veh & $77.09 \pm 0.80$ & $50.920 \pm 0.851$ & $9.66 \pm 0.04$ \\
\hline Nicotine & $68.28 \pm 1.74$ & $47.46 \pm 2.57$ & $8.98 \pm 0.09 \mathrm{a}^{\mathrm{a}^{\star \star}}$ \\
\hline Ethanol & $68.87 \pm 1.60$ & $44.91 \pm 2.63$ & $9.24 \pm 0.08^{\mathrm{a}^{\star \star}}$ \\
\hline Nic+Ethn & $72.45 \pm 1.56$ & $52.20 \pm 1.45$ & $9.23 \pm 0.08^{\mathrm{a}^{\star \star}}$ \\
\hline
\end{tabular}

Superscript letter (a) indicates a significant difference compared to the vehicle group. $* *$ and $* * *$ indicate $p \leq 0.01$ and $p \leq 0.001$, respectively. Data present Mean \pm SEM.

\section{Seminiferous tubules area}

The results of measuring seminiferous tubules area in the testes of 90 day- old offspring did not exhibit a significant statistical difference in any of the exposed groups when compared to that of the vehicle group 
(Table 2).

\section{Semi-quantitative analysis of spermatogenesis by Johnsen's score}

The result of Johnsen's score evaluation is illustrated in Table 2. The average of Johnsen's score for the seminiferous tubules in the Veh group was $9.66 \pm 0.04$ and reduced significantly to $8.98 \pm 0.09$ ( $p=$ $0.000), 9.24 \pm 0.08(p=0.003)$ and $9.23 \pm 0.08(p=0.002)$ in the Nic, Ethn and Nic+Ethn groups, respectively, relative to the Vehicle's score.

\section{Sperm quantitative analysis}

\section{Sperm number}

The sperm number was significantly reduced in the Nic group $(6.36 \pm 1.10, p=0.01)$ and slightly in the Ethn $(14.45 \pm 2.14, p=0.80)$ and the Nic+Ethn $(16.31 \pm 3.11, p=0.99)$ groups in comparison to that of the Veh $(17.32 \pm 2.41)$ group. However, a significant difference in the sperm number was observed between the Nic and Nic+Ethn groups as well $(p=0.02)$, (Fig 2-A).

As shown in Figure 2-B, the mean percentage of sperm motility was $55.37 \pm 4.60$ in the Veh group. Motility significantly decreased to $34.37 \pm 4.49(p=0.012), 28.87 \pm 4.61(p=0.001)$ and $37.00 \pm 4.06$ $(p=0.039)$ in the Nic, Ethn and Nic+Ethn groups, respectively.

\section{Sperm viability}

Analysis of the sperm viability data showed that there was a significant decrease in the number of viable sperm in the Nic (12.14 $\pm 1.80, p=0.000)$, Ethn $(14 \pm 1.65, p=0.000)$ and Nic+Ethn $(16.75 \pm 2.37, p=0.002)$ groups in comparison with the Veh group $(33 \pm 4.54)$ (Fig 2-C).

\section{Sperm DNA fragmentation (SCD)}

The result of sperm chromatin dispersion test is listed in Figure 3 A-B. In utero and lactation period exposure to nicotine $(58.5 \pm 6.44, p=0.007)$ and alcohol $(47.71 \pm 8.84, p=0.06)$, either alone or concomitant $(32.5 \pm 5.23, p=0.756)$ has led to a rise in the mean percentage of the sperm DNA fragmentation.in addition, there was a significant difference between the Nic and Nic+Ethn groups considering SCD parameter $(p=0.05)$.

The level of malondealdehyde (MDA) as an oxidative stress biomarker in all exposed pups was found to be significantly higher than those of the vehicle' serum ( $p=0.000)$ (Fig. 3C).

\section{Quantitative RT-PCR analysis for the expression of DNA Methylation regulators}

The expression level of DNMTs (1, 3A and 3B) in the sperm cells of F1 pups was measured and compared to the values of the vehicle group. The results are shown in Figure 4. In the sperm cells of nicotine $(p=0.05)$ and ethanol $(p=0.247)$, alone and concurrently $(p=0.01)$, DNMT3A expression was 
decreased compared to the vehicle pups. Furthermore, the expression level of DNMT3B in the sperm cells of all exposed mice increased and the nicotine group showed a higher level than those of other groups $(p=0.07)$, nevertheless it did not reach a significant level. Based on the DNMT1 expression, there was no marked alteration in the sperm cells when compared to the vehicle $(p=0.869,0.343$ and 0.666 compared to the Nic, Ethn and Nic+Ethn groups, respectively).

In the sperm cells of F1 pups, changes in the expression of HDACs (1 and 2) genes were also measured (Figure 5). In comparison with the unexposed mice, the expression levels of HDAC1 and HDAC2 were markedly increased by maternal exposure to nicotine $(p=0.001, p=0.002)$ and ethanol $(p=0.000, p=0.04)$, either alone or concomitant $(p=0.003, p=0.178)$, respectively. However, concurrent-exposed pups showed alleviated changes in mRNAs expression of histone hypoacetylation regulators compared with nicotine or alcohol-exposed pups, so that a significant difference in the expression level of HDAC2 was observed between the Nic and Nic+Ethn groups ( $p=0.026$ ) (Fig. 5).

\section{Discussion}

The findings of this study revealed that exposure of F1 pups to nicotine, alcohol and their combination during in-utero and locational period could change postnatal sperm and testicular parameters as well as germ cell epigenetic modifying enzymes expression. Interestingly, co-administration of these substances to F1 pups alleviated the negative effects of nicotine and alcohol alone.

In the current study, Johnsen score's data showed a decrease of spermatogenesis activity in the testes of alcohol and particularly nicotine-exposed pups which are in line with previous studies documenting the transgenerational adverse effects of these substances on spermatogenesis ${ }^{8,33}$.Another study has also reported that exposure to ethanol during late prenatal and breastfeeding periods could delay the onset of spermatogenesis in young ${ }^{33}$ and adult male offspring ${ }^{34}$. Disturbed spermatogenesis in the nicotineexposed offspring is due to complex mechanisms such as a decrease in the expression level of Sertolicell-specific desert hedgehog gene ${ }^{35}$, dysmorpho-function of Sertoli cells; nursing cell of spermatogenic cell lines ${ }^{36}$, increase of gonocyte and meiotic germ cell apoptosis ${ }^{36}$, reduction of the spermatogonial stem cell population ${ }^{36}$ as well as deficits of seminiferous tubule organization ${ }^{8}$. In regard to in utero exposure to alcohol, fetal Sertoli cell development disruption ${ }^{37} 38$ and a fewer number of primordial germ cells in tsetse of neonates ${ }^{33}$ may be partially explained the offspring's disturbed spermatogenesis. In addition to, in an another study ${ }^{33}$ suggested that direct harmful effect of ethanol on developing reproductive system may lead to spermatogenesis disruption.

A lower sperm number, especially in the nicotine-exposed offspring, was observed in our study. Several previous studies showed a significant decrease of sperm number after prenatal exposure to nicotine and ethanol ${ }^{8,13}$. We also observed a lower sperm motility in all exposed offspring, particularly, in the ethanolexposed pups. Consistent with decreased motility, analysis of serum MDA level; as a final lipid peroxidation (LP) product and oxidative stress marker showed a significant increase in all exposed 
offspring. Oxidative stress occurs when there is an imbalance between reactive oxidizing species (ROS) production and antioxidant defenses. This imbalance was reported in the pregnant mothers 39,40 and infants ${ }^{39-42}$ that were exposed to ethanol and smoke. A previous study has ${ }^{43}$ reported that maternal smoking could reduce antioxidants levels such as vitamin E and A in milk, therefore, the antioxidant status of newborns is also diminished. However, among sperm parameters, it seems that sperm motility ${ }^{44}$ and DNA integrity ${ }^{45}$ are more vulnerable to non-physiologic levels of ROS. Sperm membrane is rich in polyunsaturated fatty acids. This characteristic makes it vulnerable to ROS-induced LP. This process can cause structural changes of sperm membrane and motility apparatus housed within the sperm flagellum, as well as alteration of biophysical features such as diminished activity of sodium/potassium ATP; an essential pump for motility ${ }^{46}$. Moreover, since normal mitochondria function is in a part, necessary for sperm motility, and ROS-mediated disturbed mitochondria membrane integrity ${ }^{47}$ could affect its proper function, hence mitochondrial dysfunction in the nicotine-exposed-F1 male ${ }^{8}$ could be one of the possible reasons for decreased sperm motility. Also, a decrease in the expression level of genes involved in sperm flagellum formation and development, or the other structures related to motility efficiency might be another mechanisms ${ }^{36}$.

Oxidative stress could affect genome integrity ${ }^{48}$. In agreement with a previous report ${ }^{8}$, we observed high frequencies of sperm DNA fragmentation (SDF) in the all exposed animals, being highest in the nicotineexposed offspring. Since, high level of ROS production and diminished activity of antioxidant molecules could lead to oxidative stress, the highest SDF level in the nicotine-exposed offspring, in comparison to other exposed mice, may be a result of a lower level of antioxidant defense activity $40,49,50$. We assume that oxidative stress resulting from these toxins could affect germline lineage genome during early life, leading to disruption of gamete DNA integrity of adult males. Moreover, we observed a less deleterious effect in the ethanol-exposed mice in comparison with nicotine. Since the nicotine in fetus bloodstream has higher level than that of smoking mother ${ }^{51}$, hence this may be a causal explanation for more permanent effects of nicotine rather than ethanol. On the one hand, the ethanol effects were applied in a dose-dependent manner ${ }^{52}$; the dosage used in our experiments was equivalent to that of serum after moderate drinking ${ }^{53}$, so it appears that ethanol, at this dose, had a slighter negative effect than nicotine. Also, it is reported that alcohol at low and moderate doses could increase heat shock proteins ${ }^{54,55}$. These proteins could inhibit apoptosis and facilitate cell recovery via inhibition of the caspase cascade and proapoptotic proteins activity ${ }^{56}$, which could limit inflammation as well as cell death. Taken together, the decreased sperm parameters and spermatogenesis changes may lead to a lower fertility potential in the F1 offspring after exposure to nicotine or alcohol. However, for the first time, we observed mildly effects of concurrently exposure to these substances on $\mathrm{F} 1$ male reproductive properties in comparison with exposure to each one, alone as co-exposure to these substances showed a lighter reduction of sperm motility. In line with our findings, a previous study reported an improvement of cognitive impairment in alcohol drinking subjects by smoking ${ }^{57}$. Nicotine is considered to be responsible for such alleviating effects ${ }^{58,59}$. Another study also showed that alcohol toxification is lower in chronic smokers compared to that of the non- smokers ${ }^{60}$. Recently, Bhattacharya and colleagues ${ }^{61}$ showed that prenatal ethanol 
exposure ( $10 \% \mathrm{v} / \mathrm{v})$ could increase ROS production, LP, caspases activities as well as decrease spatial memory in F1 rats, while simultaneous exposure to ethanol and nicotine ( $6 \mathrm{mg} / \mathrm{kg} / \mathrm{day}$, by mini pump) could alleviate the adverse effects of ethanol on oxidative stress and hippocampal memory. However, they exposed pregnant rats to nicotine and ethanol at higher and lower doses, respectively compared to our study. Although the exact alleviating mechanism still is not fully understood, Hurley and co-workers 62 explained that the dose and also co-use of these substances could change the adverse effects of each, alone ${ }^{63}$ by alteration of peripheral metabolism of the other ${ }^{64,65}$. Several mechanisms such as modulation of calcium, anti-apoptotic mechanism and also nitric oxide signaling ${ }^{58}$ were reported to improve the effects between these two determents. Yet, some studies determined that this counteracting effect was only observed in acute exposure dose ${ }^{66}$ and in contrast, some reported a synergistically contribution of these drugs ${ }^{67}$ in impairment even in acute dose exposure. In contrast to our findings, Sabzalizadeh and co-workers ${ }^{68}$ revealed that these two substances could synergistically impair cognition in pups. However, it is yet unknown that whether such a different effect is dependent on the developing tissue; so that the interaction of these substances during embryofoetal life might differently affect cells in developing reproductive system rather than the nervous system. Confirmation of this hypothesis need further investigations.

On the other hand, the widespread reprogramming of male gamete in in utero development period ${ }^{69}$ makes it sensitive to environmental and chemical factors. Many studies have investigated the effects of nicotine and ethanol, alone, on the epigenetic signature of developing fetus and neonates as well as male gamete. However, the findings are controversial and the effect of concurrently maternal and lactational exposure to these substances has not yet been elucidated. Therefore, we examined the possible epigenetic modifications by the expression level assessment of a diversity of modifying enzymes; DNMTs and HDACs in the exposed offspring's sperm cells. Our data provides evidences that in utero and lactational exposure to alcohol and nicotine markedly decrease DNMT3a transcripts and significantly increase HDACs (1 and 2) transcripts of the sperm cells. Interestingly, we noted that alcohol and nicotine co-exposure had less obvious effect on these enzymes levels compared with alcohol and nicotine, alone. Previous studies have reported that exposure of fetus to alcohol could change chromatin structure and epigenetic signature in GD 17 developing fetal brain of mice ${ }^{70}$, global DNA hypomethylation of fetus genome ${ }^{31}$, obvious diminished DNMT activity ${ }^{30,31}$, hypomethylation of imprinted gene; $\mathrm{H} 19$, elevated histone 3 acetylation in lung ${ }^{71}$, and cardiac cells ${ }^{72}$ as well as reduced HAT activity in cerebellum ${ }^{73}$. These alterations suggested a strong correlation between this epigenetic signatures with congenital malformations' attendance. A recent study ${ }^{74}$ exposed pregnant Wistar rats to alcohol $(4 \mathrm{mg} / \mathrm{kg} / \mathrm{daily}$, 920 GD days) to evaluate the epigenetic mechanism involved in testicular function of F1 pups. They showed that testicular dysplasia due to elevated corticosterone level was associated with low-functional

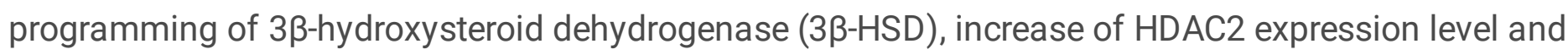
also decrease of histone 3 lysine 14 (H3K14ac) acetylation. We also observed a marked increase in the HDACs transcripts in the ethanol-exposed offspring's sperm cells. Gangisetty and co-workers ${ }^{75}$ demonstrated that in utero alcohol exposure could lead to pituitary changes via epigenetic mechanism. 
Although, in agreement with our data, they observed a significant increase in HDAC2, but they also reported a significant increase in pituitary mRNA level of DNMT 1 and 3b, while we did not observe such transcripts changes in sperm cells of exposed pups. In some studies, oxidative stress after acute ethanol use ${ }^{76}$, and also reduction of methyl donors such as s-adenosylmethionine (SAM) for DNMTs following its chronic use ${ }^{77}$ are explained as some of ethanol mechanisms as a modifier of DNA methylation signature in sperm cells which represents into global DNA hypomethylation.

Meanwhile, multiple experimental and clinical studies have reported the effects of maternal exposure to smoking on epigenetic alterations in various tissue of exposed fetus, newborns, children and adolescent. However, for the first time, we found the changes of sperm cell's mRNA level of HDAC1 and 2. A previous study ${ }^{78}$ determined that second-trimester fetuses of active smoker mothers had different DNA methylation state as well as reduction of neuronal proportion in the developing brain prefrontal cortex. They suggested that nicotine, is responsible for such effects. Another recent study revealed that in utero exposure to smoking led to differentially DNA methylation in 10,381 CpGs sites of cord blood CD41 positive cells of newborns ${ }^{20}$ as well as 69 CpGs sites ${ }^{29}$ in 36 genomic regions of adult offspring blood cells. Moreover, Rehan and collagenous ${ }^{79}$ observed that prenatal exposure to nicotine $(1 \mathrm{mg} / \mathrm{kg})$ could increase DNA methylation and $\mathrm{H} 3$ and $\mathrm{H} 4$ acetylation in F1 offspring's testicular cells. They showed a transmission of germline epigenetic marks to F2 offspring. However, based on our results, it appears that exposure to these substances may affect histone deacetylation level of sperm cells more than DNA methylation. Histone alterations in sperm cells might cause abnormal further generation development, gene expression and phenotype ${ }^{80,81}$. Besides that, in line with almost our entire dataset, simultaneous exposure to these detrimental substances had a slighter effect on the expression level of epigenetic modifying enzymes in comparison to exposure to these substance, alone.

In conclusion, the present study revealed that in utero and lactational exposure to ethanol and nicotine could trigger changes in the sperm properties and interestingly, for the first time, presented an unusual alleviating effect of co-exposure to these substances on F1 offspring's reproductive system. However, there are still many questions about how the interaction of these drugs could counteract the negative effects of one drug by the other. Therefore, further studies especially at the molecular level are needed. Moreover, our findings revealed changes in the expression level of epigenetic modifying enzymes included DNMT3A, HDAC 1 and 2 in the sperm cells of F1 offspring exposed mice. These transcripts changes could associate by aberrant germline epigenetic alterations. What make these findings even more important, is the potential of transgenerational transmission of these epigenetic changes via exposed germline to the next generation.

\section{Declarations}

\section{Acknowledgment}

The authors thank Neuroscience Research Center, Institute of Neuropharmacology, Kerman University of Medical Sciences, Kerman, Iran for financial support of this study. 
Author contributions

A.P. and S.G.H. conducted the experiment (s), E.M. performed animal treatment, S.N.N.M., M.E. and M.R.A contributed to the manuscript, A.A. designed primer, T.H. conceived the experiments and wrote the manuscript. All authors reviewed the manuscript.

\section{Additional Information}

\section{Competing of interest}

The authors declare no competing interests.

\section{References}

1. Espinet, C. \& Argiles, J. Ethanol and acetaldehyde concentrations in the rat foeto-maternal system after an acute ethanol administration given to the mother. Arch Int Physiol Biochim Biophys 92, 339344 (1984).

2. Slotkin, T. A. Fetal nicotine or cocaine exposure: which one is worse? J Pharmacol Exp Ther 285, 931945 (1998).

3. Lawton, M. E. Alcohol in breast milk. Aust N Z J Obstet Gynaecol 25, 71-73 (1985).

4. Ferguson, B. B., Wilson, D. J. \& Schaffner, W. Determination of nicotine concentrations in human milk. American Journal of Diseases of Children 130, 837-839 (1976).

5. Bar-Zeev, Y., Lim, L. L., Bonevski, B., Gruppetta, M. \& Gould, G. S. Nicotine replacement therapy for smoking cessation during pregnancy. Med J Aust 208, 46-51 (2018).

6. Sanders, J. L. Were our forebears aware of prenatal alcohol exposure and its effects? A review of the history of fetal alcohol spectrum disorder. J Popul Ther Clin Pharmacol 16, e288- e295 (2009).

7. Mamsen, L. S. et al. Cigarette smoking during early pregnancy reduces the number of embryonic germ and somatic cells. Human reproduction 25, 2755-2761 (2010).

8. Miranda-Spooner, M., Paccola, C., Neves, F., de Oliva, S. \& Miraglia, S. Late reproductive analysis in rat male offspring exposed to nicotine during pregnancy and lactation. Andrology 4, 218-231 (2016).

9. Ramlau-Hansen, C. et al. Maternal alcohol consumption during pregnancy and semen quality in the male offspring: two decades of follow-up. Hum Reprod 25, 2340-2345 (2010).

10. Ravnborg, T. L. et al. Prenatal and adult exposures to smoking are associated with adverse effects on reproductive hormones, semen quality, final height and body mass index. Hum Reprod 26, 1000-1011 (2011).

11. Ramlau-Hansen, C. H. et al. Is prenatal exposure to tobacco smoking a cause of poor semen quality? A follow-up study. American journal of epidemiology 165, 1372-1379 (2007).

12. Ratcliffe, J. M., Gladen, B. C., Wilcox, A. J. \& Herbst, A. L. Does early exposure to maternal smoking affect future fertility in adult males? Reproductive toxicology 6, 297-307 (1992). 
13. Lagunov, A. et al. Effect of in utero and lactational nicotine exposure on the male reproductive tract in peripubertal and adult rats. Reprod Toxicol 31, 418-423 (2011).

14. Burton, S. M. \& Tiffany, S. T. The effect of alcohol consumption on craving to smoke. Addiction $\mathbf{9 2}$, 15-26 (1997).

15. Bien, T. H. \& Burge, R. Smoking and drinking: a review of the literature. Int J Addict 25, 1429-1454 (1990).

16. DiFranza, J. R. \& Guerrera, M. P. Alcoholism and smoking. J. Stud. Alcohol 51, 130-135 (1990).

17. McKee, S. A. \& Weinberger, A. H. How can we use our knowledge of alcohol-tobacco interactions to reduce alcohol use? Annu Rev Clin Psycho/ 9, 649-674 (2013).

18. John, U., Meyer, C., Rumpf, H. J. \& Hapke, U. Probabilities of alcohol high-risk drinking, abuse or dependence estimated on grounds of tobacco smoking and nicotine dependence. Addiction 98, 805814 (2003).

19. Woo, N. D. \& Persaud, T. Rat embryogenesis following exposure to alcohol and nicotine. Cells Tissues Organs 131, 122-126 (1988).

20. Howe, C. G. et al. Associations between Maternal Tobacco Smoke Exposure and the Cord Blood CD 4+ DNA Methylome. Environ. Health Perspect. 127, 047009 (2019).

21. Leslie, F. M. Multigenerational epigenetic effects of nicotine on lung function. BMC medicine 11, 1-4 (2013).

22. Baccarelli, A. \& Bollati, V. Epigenetics and environmental chemicals. Curr Opin Pediatr 21, 243 (2009).

23. Wilhelm-Benartzi, C. S. et al. In utero exposures, infant growth, and DNA methylation of repetitive elements and developmentally related genes in human placenta. Environmental health perspectives 120, 296-302 (2012).

24. Chastain, L. G. \& Sarkar, D. K. Alcohol effects on the epigenome in the germline: Role in the inheritance of alcohol-related pathology. Alcohol 60, 53-66 (2017).

25. Zakarya, R., Adcock, I. \& Oliver, B. G. Epigenetic impacts of maternal tobacco and e-vapour exposure on the offspring lung. Clinical Epigenetics 11, 1-11 (2019).

26. Rauschert, S. et al. Maternal smoking during pregnancy induces persistent epigenetic changes into adolescence, independent of postnatal smoke exposure and is associated with cardiometabolic risk. Frontiers in genetics 10, 770 (2019).

27. Banik, A. et al. Maternal factors that induce epigenetic changes contribute to neurological disorders in offspring. Genes 8, 150 (2017).

28. Vaissière, T., Sawan, C. \& Herceg, Z. Epigenetic interplay between histone modifications and DNA methylation in gene silencing. Mutat Rer-Rev Mutat 659, 40-48 (2008).

29. Wiklund, P. et al. DNA methylation links prenatal smoking exposure to later life health outcomes in offspring. Clin Epigenetics 11, 97 (2019).

30. Haycock, P. C. \& Ramsay, M. Exposure of mouse embryos to ethanol during preimplantation development: effect on DNA methylation in the h19 imprinting control region. Biol. Reprod. 81, 618- 
627 (2009).

31. Garro, A. J., McBeth, D. L., Lima, V. \& Lieber, C. S. Ethanol consumption inhibits fetal DNA methylation in mice: implications for the fetal alcohol syndrome. Alcohol Clin Exp Res 15, 395-398 (1991).

32. Stouder, C., Somm, E. \& Paoloni-Giacobino, A. Prenatal exposure to ethanol: a specific effect on the H19 gene in sperm. Reprod Toxicol 31, 507-512 (2011).

33. Lan, N., Vogl, A. W. \& Weinberg, J. Prenatal ethanol exposure delays the onset of spermatogenesis in the rat. Alcoholism: Clinical and Experimental Research 37, 1074-1081 (2013).

34. Onu, J., Ezeasor, D. \& Ihemelandu, E. Histological evidence of retardation of spermatogenesis in mice in experimentally induced fetal alcohol syndrome. Pak J Biol Sci(2003).

35. Fowler, P. A. et al. Maternal smoking during pregnancy specifically reduces human fetal desert hedgehog gene expression during testis development. J Clin Endocrinol Metab 93, 619-626 (2008).

36. Sobinoff, A. P. et al. Damaging legacy: maternal cigarette smoking has long-term consequences for male offspring fertility. Hum Reprod 29, 2719-2735 (2014).

37. Sharpe, R. M., McKinnell, C., Kivlin, C. \& Fisher, J. S. Proliferation and functional maturation of Sertoli cells, and their relevance to disorders of testis function in adulthood. Reproduction 125, 769-784 (2003).

38. Li, H. \& Kim, K. H. Effects of ethanol on embryonic and neonatal rat testes in organ cultures. J. Androl. 24, 653-660 (2003).

39. Aydogan, U. et al. Effects of smoking during pregnancy on DNA damage and ROS level consequences in maternal and newborns' blood. J Ind Hyg Toxicol 64, 35-46 (2013).

40. Chelchowska, M., Ambroszkiewicz, J., Gajewska, J., Laskowska-Klita, T. \& Leibschang, J. The effect of tobacco smoking during pregnancy on plasma oxidant and antioxidant status in mother and newborn. Eur J Obstet Gynecol Reprod Biol X 155, 132-136 (2011).

41. Ermis, B. et al. Influence of smoking on maternal and neonatal serum malondialdehyde, superoxide dismutase, and glutathione peroxidase levels. Ann Clin Lab Sci 34, 405-409 (2004).

42. Marianian, A. et al. The effect of low alcohol consumption during pregnancy on the lipid peroxidation-antioxidant defense system of women, their alcohol-exposed infants, and growth, health, and developmental outcomes. Birth Defects Res 112, 40-53 (2020).

43. Orhon, F. S. et al. The influence of maternal smoking on maternal and newborn oxidant and antioxidant status. Eur J Pediatr 168, 975-981 (2009).

44. Nowicka-Bauer, K. \& Nixon, B. Molecular Changes Induced by Oxidative Stress that Impair Human Sperm Motility. Antioxidants 9, 134 (2020).

45. Bisht, S., Faiq, M., Tolahunase, M. \& Dada, R. Oxidative stress and male infertility. Nat. Rev. Urol. 14, 470 (2017).

46. Baker, M. A. et al. Defining the Mechanisms by Which the Reactive Oxygen Species by-Product, 4Hydroxynonenal, Affects Human Sperm Cell Function. Biol. Reprod. 92, 108-101 (2015). 
47. Stewart, V. C. \& Heales, S. J. Nitric oxide-induced mitochondrial dysfunction: implications for neurodegeneration. Free Radic Biol Med 34, 287-303 (2003).

48. Wright, C., Milne, S. \& Leeson, H. Sperm DNA damage caused by oxidative stress: modifiable clinical, lifestyle and nutritional factors in male infertility. Reprod Biomed Online 28, 684-703 (2014).

49. Ajarem, J. S., Al-Basher, G., Allam, A. A. \& Mahmoud, A. M. Camellia sinensis prevents perinatal nicotine-induced neurobehavioral alterations, tissue injury, and oxidative stress in male and female mice newborns. Oxid. Med. Cell. Longev 2017 (2017).

50. Kurt, A., Kurt, A., Benzer, D., Aygün, A. \& Ustündag, B. Exposure to Environmental Tobacco Smoke during Pregnancy Restrain the Antioxidant Response of their Neonates. . J. Neonatal Bio/ 5, 1000210 (2016).

51. Luck, W., Nau, H., Hansen, R. \& Steldinger, R. Extent of nicotine and cotinine transfer to the human fetus, placenta and amniotic fluid of smoking mothers. Dev Pharmacol Ther 8, 384-395 (1985).

52. Donnelly, G., McClure, N., Kennedy, M. \& Lewis, S. Direct effect of alcohol on the motility and morphology of human spermatozoa. Andrologia 31, $43-47$ (1999).

53. Schambra, U. B. et al. Low and moderate prenatal ethanol exposures of mice during gastrulation or neurulation delays neurobehavioral development. Neurotoxicol Teratol 51, 1-11 (2015).

54. Pignataro, L. Alcohol protects the CNS by activating HSF1 and inducing the Heat Shock Proteins. Neurosci. Lett 713, 134507 (2019).

55. Sivaswamy, S., Neafsey, E. J. \& Collins, M. A. Neuroprotective preconditioning of rat brain cultures with ethanol: potential transduction by PKC isoforms and focal adhesion kinase upstream of increases in effector heat shock proteins. Eur. J. Neurosci. 32, 1800-1812 (2010).

56. Beere, H. M. The stress of dying': the role of heat shock proteins in the regulation of apoptosis. J. Cell Sci. 117, 2641-2651 (2004).

57. Ceballos, N. A. Tobacco use, alcohol dependence, and cognitive performance. J Gen Psychol. 133, 375-388 (2006).

58. Taslim, N., Soderstrom, K. \& Dar, M. S. Role of mouse cerebellar nicotinic acetylcholine receptor (nAChR) a4ß2-and a7 subtypes in the behavioral cross-tolerance between nicotine and ethanolinduced ataxia. Behav Brain Res 217, 282-292 (2011).

59. Al-Rejaie, S. \& Dar, M. S. Antagonism of ethanol ataxia by intracerebellar nicotine: possible modulation by mouse cerebellar nitric oxide and cGMP. Brain Res. Bull. 69, 187-196 (2006).

60. Madden, P. A., Bucholz, K. K., Martin, N. G. \& Heath, A. C. Smoking and the genetic contribution to alcohol-dependence risk. Alcohol Res. Health. 24, 209 (2000).

61. Bhattacharya, D. et al. Concurrent nicotine exposure to prenatal alcohol consumption alters the hippocampal and cortical neurotoxicity. Heliyon 6, e03045 (2020).

62. Hurley, L. L., Taylor, R. E. \& Tizabi, Y. Positive and negative effects of alcohol and nicotine and their interactions: a mechanistic review. Neurotox. Res. 21, 57-69 (2012). 
63. Lajtha, A. \& Sershen, H. Nicotine: alcohol reward interactions. Neurochem. Res. 35, 1248-1258 (2010).

64. Yue, J., Khokhar, J., Miksys, S. \& Tyndale, R. F. Differential induction of ethanol-metabolizing CYP2E1 and nicotine-metabolizing CYP2B1/2 in rat liver by chronic nicotine treatment and voluntary ethanol intake. Eur. J. Pharmacol. 609, 88-95 (2009).

65. Parnell, S. E., West, J. R. \& Chen, W. J. A. Nicotine decreases blood alcohol concentrations in adult rats: a phenomenon potentially related to gastric function. Alcohol Clin Exp Res 30, 1408-1413 (2006).

66. Craddock, A., Cheek, J., Tivis, R. \& Nixon, S. Nicotine's effects on neurocognitive performance in alcoholics. Alcohol Clin Exp Res 27, 140A (2003).

67. Bizarro, L., Patel, S. \& Stolerman, I. Comprehensive deficits in performance of an attentional task produced by co-administering alcohol and nicotine to rats. Drug Alcohol Depend. 72, 287-295 (2003).

68. Sabzalizadeh, M. et al. Alcohol and nicotine co-Administration during pregnancy and lactation periods alters sensory discrimination of adult NMRI mice offspring. Physiol. Behav. 213, 112731 (2020).

69. Ungerer, M., Knezovich, J. \& Ramsay, M. In utero alcohol exposure, epigenetic changes, and their consequences. Alcohol Res 35, 37 (2013).

70. Veazey, K. J., Parnell, S. E., Miranda, R. C. \& Golding, M. C. Dose-dependent alcohol-induced alterations in chromatin structure persist beyond the window of exposure and correlate with fetal alcohol syndrome birth defects. Epigenetics Chromatin 8, 39 (2015).

71. Wang, X., Gomutputra, P., Wolgemuth, D. J. \& Baxi, L. V. Acute alcohol exposure induces apoptosis and increases histone H3K9/18 acetylation in the mid-gestation mouse lung. Reprod Sci. 17, $384-390$ (2010).

72. Zhong, L. et al. Ethanol and its metabolites induce histone lysine 9 acetylation and an alteration of the expression of heart development-related genes in cardiac progenitor cells. Cardiovasc. Toxicol. 10, 268-274 (2010).

73. Guo, W. et al. Alcohol exposure decreases CREB binding protein expression and histone acetylation in the developing cerebellum. PloS one 6 (2011).

74. Liu, M. et al. Corticosterone rather than ethanol epigenetic programmed testicular dysplasia caused by prenatal ethanol exposure in male offspring rats. Epigenetics 14, 245-259 (2019).

75. Gangisetty, O., Wynne, O., Jabbar, S., Nasello, C. \& Sarkar, D. K. Fetal alcohol exposure reduces dopamine receptor D2 and increases pituitary weight and prolactin production via epigenetic mechanisms. PloS one 10 (2015).

76. Tunc, O. \& Tremellen, K. Oxidative DNA damage impairs global sperm DNA methylation in infertile men. J Assist Reprod Genet 26, 537-544 (2009).

77. Kruman, I. I. \& Fowler, A. K. Impaired one carbon metabolism and DNA methylation in alcohol toxicity. J Neurochem 129, 770-780 (2014). 
78. Chatterton, Z. et al. In utero exposure to maternal smoking is associated with DNA methylation alterations and reduced neuronal content in the developing fetal brain. Epigenetics Chromatin 10, 4 (2017).

79. Rehan, V. K. et al. Perinatal nicotine exposure induces asthma in second generation offspring. BMC Med. 10, 129 (2012).

80. Carrell, D. T. \& Hammoud, S. S. The human sperm epigenome and its potential role in embryonic development. Mol Hum Reprod 16, 37-47 (2009).

81. Siklenka, K. et al. Disruption of histone methylation in developing sperm impairs offspring health transgenerationally. Science $\mathbf{3 5 0}$ (2015).

82. Levin, E. D., Wilkerson, A., Jones, J. P., Christopher, N. C. \& Briggs, S. J. Prenatal nicotine effects on memory in rats: pharmacological and behavioral challenges. Dev. Brain Res. 97, 207-215 (1996).

83. Zare, M., Haghpanah, T., Shekari, M. A. \& Eftekhar-Vaghefi, S. H. The prophylactic effect of date palm (Phoenix dactylifera L.) fruit extract on testicular toxicity induced by formaldehyde: An experimental study. Int J Reprod Biomed 18, 275 (2020).

84. Hakemi, S. G., Sharififar, F., Haghpanah, T., Babaee, A. \& Eftekhar-Vaghefi, S. H. The effects of olive leaf extract on the testis, sperm quality and testicular germ cell apoptosis in male rats exposed to busulfan. Int J Fertil Steril 13, 57 (2019).

85. Saddein, E., Haghpanah, T., Nematollahi-Mahani, S. N., Seyedi, F. \& Ezzatabadipour, M. Preventative effects of vitamin $E$ on testicular damage and sperm parameters in the first-generation mice pups due to pre-and postnatal mancozeb exposure. J Toxicol 2019 (2019).

86. Salehi, M., reza Afarinesh, M., Haghpanah, T., Novin, M. G. \& Farifteh, F. Impact of sperm DNA fragmentation on ICSI outcome and incidence of apoptosis of human pre-implantation embryos obtained from in vitro matured MIl oocytes. Biochem Biophys Res Commun 510, 110-115 (2019).

87. Haghpanah, T., Eslami-Arshaghi, T., Afarinesh, M. \& Salehi, M. Decreased fertilization: Human sperm DNA fragmentation and in vitro maturation of oocyte in stimulated ICSI cycles. Acta Endocrinol (Buchar) 13, 23 (2017).

88. Rahimipour, M., Talebi, A. R., Anvari, M., Sarcheshmeh, A. A. \& Omidi, M. Effects of different doses of ethanol on sperm parameters, chromatin structure and apoptosis in adult mice. Eur J Obstet Gynecol Reprod Biol X 170, 423-428 (2013).

89. Johnsen, S. G. Testicular biopsy score count-a method for registration of spermatogenesis in human testes: normal values and results in 335 hypogonadal males. Horm Res Paediatr 1, 2-25 (1970).

90. Pourjafari, F. et al. Protective effects of hydro-alcoholic extract of foeniculum vulgare and linum usitatissimum on ovarian follicle reserve in the first-generation mouse pups. Heliyon 5, e02540 (2019).

\section{Figures}



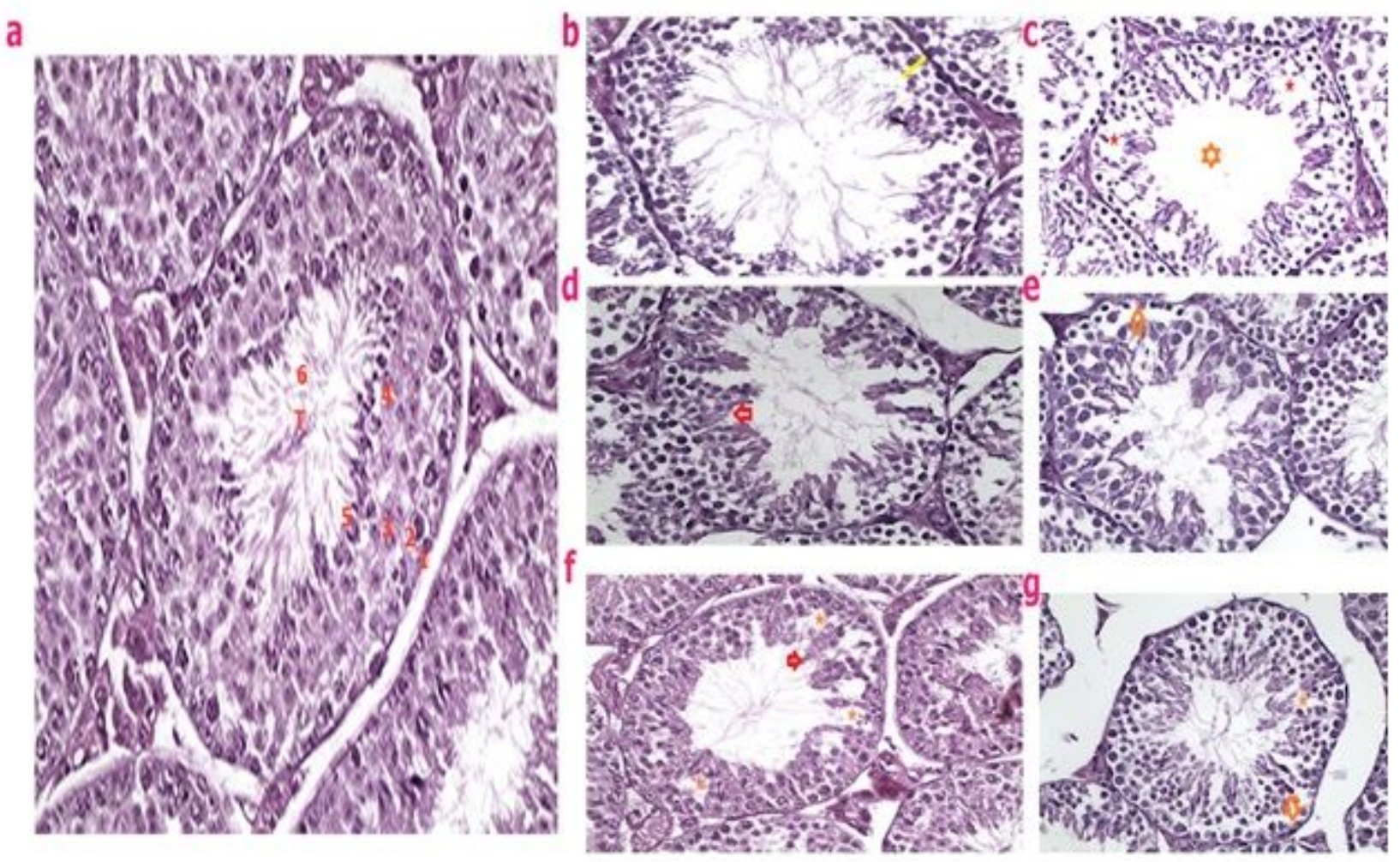

\section{Figure 1}

Photomicrographs of testicular sections of adult pups of different experimental groups submitted to the hematoxylin/eosin $Y$ staining. Normal seminiferous tubules $(T)$ with clear lumen and perfect spermatogenesis contained of various germ cells of mice from Vehicle group were observed (a). The large quantity of germinal lineage cells in a normal arrangement of cellular types including of spermatogonia (1), primary spermatocyte (2), secondary spermatocyte (3), round spermatid (4), attached sperms (5), released sperm within lumen was observed. Testis of a nicotine- exposed mice (b-e) showing severe deteriorating change and atrophy of seminiferous tubules (b, yellow line), absence (c, orange star) or reduction (d) of the sperm cells within the lumen of some seminiferous tubules with some degenerative alterations alike vacuoles (c, red stars). Note, the absence of germ cells resulting in partial depletion of the seminiferous epithelium and germinal cells atrophy (d, red arrows), sloughing germinal epithelium ( $d$, red arrow) and detached spermatogenic cells from basement membrane (e, orange arrow). Testicular sections obtained from F1 pups of dams exposed to either ethanol (f) or concurrent nicotine and ethanol (g) showing the restoration of spermatogenic cells in most seminiferous tubules, a few sperm cells in the lumen with several vacuoles in the germinal epithelium (stars). 

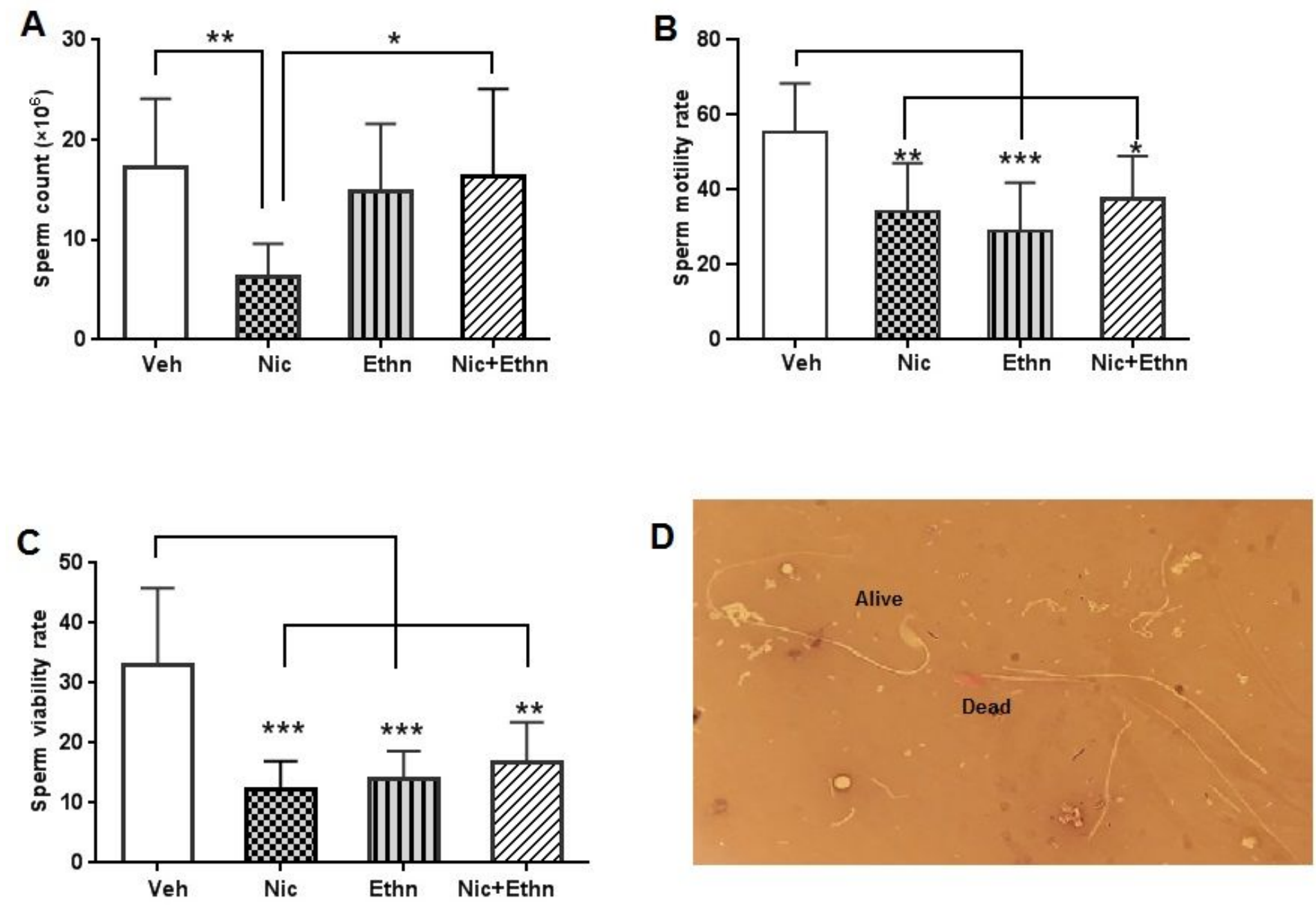

\section{Figure 2}

The effect of in utero and lactational exposure to nicotine and ethanol, either alone or concurrent, on sperm parameters of adult offspring. Sperm parameters included of sperm count (A), sperm motility (B) and sperm vitality (C). D: stained sperm with eosin $\mathrm{Y} /$ nigrosine to determine viability, alive sperm is colorless and dead sperm is pink. *, ** and $* * *$ indicate $p \leq 0.05, p \leq 0.01$ and $p \leq 0.001$. 
A

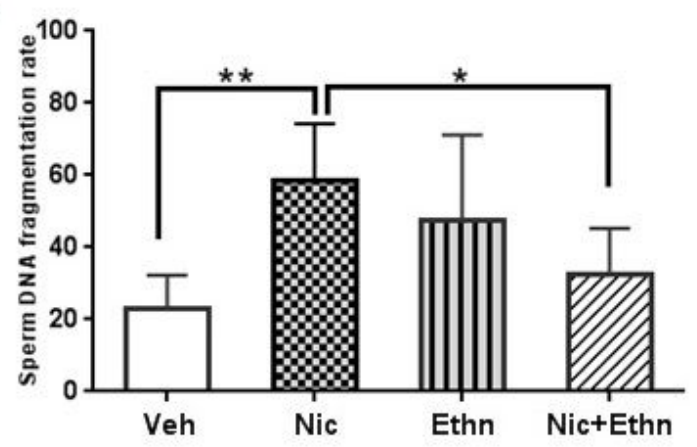

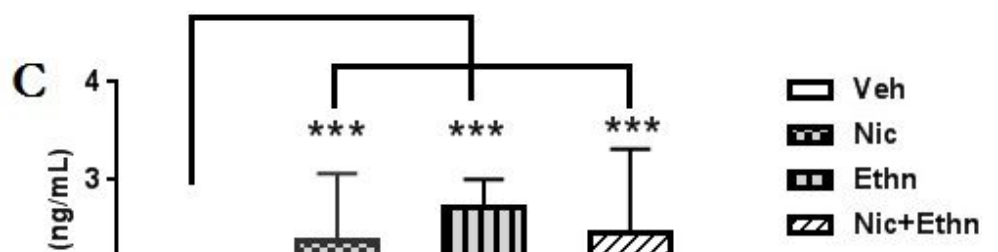

B
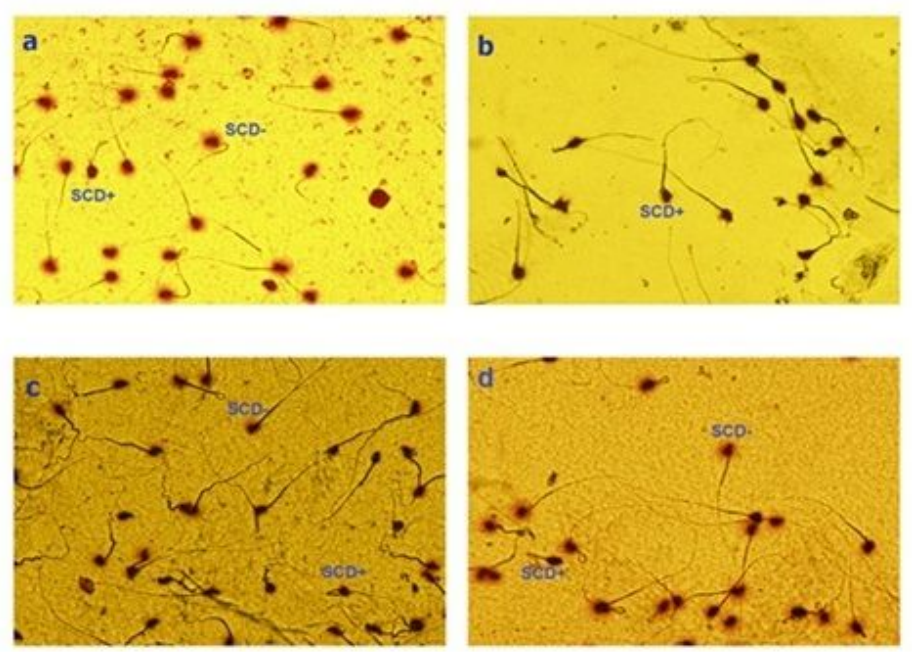

Figure 3

The effects of nicotine and ethanol exposure during embryofoetal development and breastfeeding periods on sperm DNA fragmentation (SDF). A) SDF rate in different experimental groups. B) SDF was assessed by sperm chromatin dispersion (SCD) test. SCD+ indicates sperm cells with fragmented DNA and SCD- indicates sperm cells with normal DNA integrity ( $\times 100$ eyepiece magnification). sperm cells of the Vehicle (a), nicotine-exposed (b), ethanol-exposed (c) and concurrent exposed (d) animals. C) Concentration of malondialdehyde $(\mathrm{nmol} / \mathrm{mL})$ in the serum of the ethanol and nicotine, alone or concurrent-exposed pups. ${ }^{*}{ }^{* *}$ and $* * *$ indicate $p \leq 0.05, p \leq 0.01$ and $p \leq 0.001$, respectively. 
A

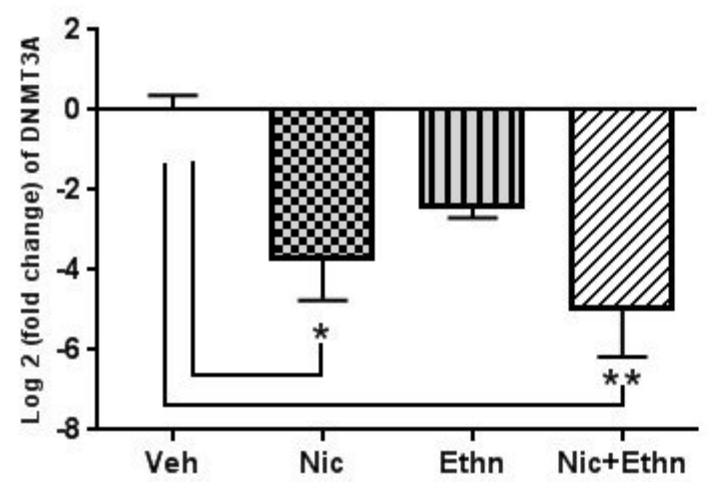

B

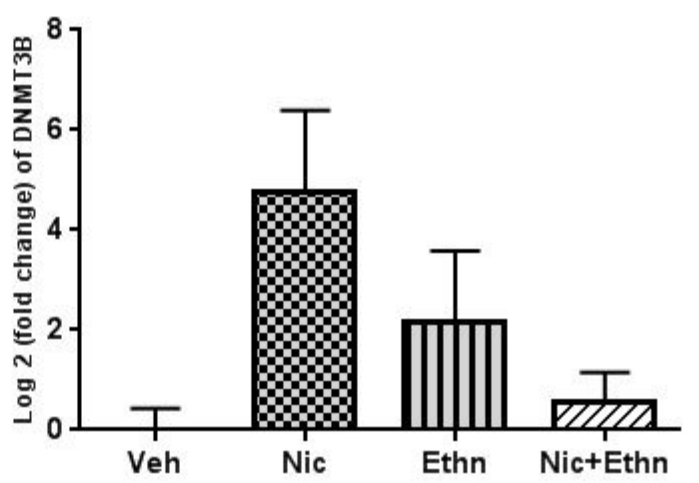

Veh

Nic

Ethn

एב Nic+Ethn

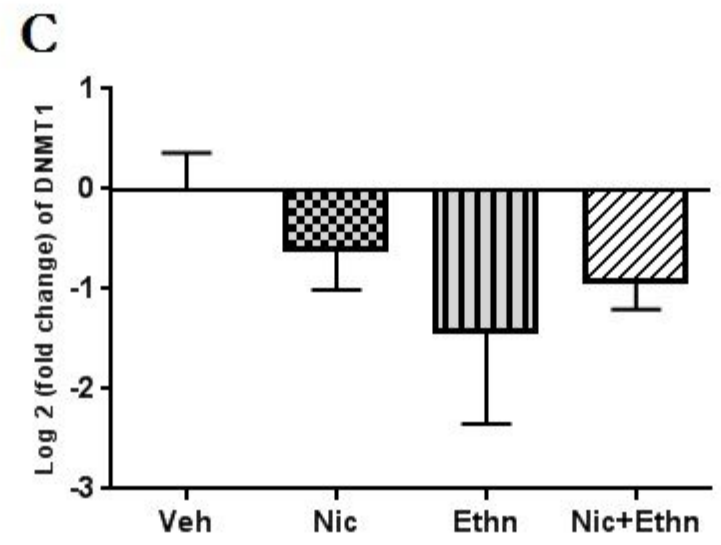

Figure 4

The effect of maternal exposure to nicotine and ethanol, alone and concurrently, on the expression level of enzymes involved in DNA methylation. Real-time quantitative PCR (RT-qPCR) analysis of DNA metyltransferases (DNMT) 1, 3A and 3B gene expression in sperm cells of F1 pups from vehicle ad treated mice. Graphs present mean \pm SEM. Data from each gene were normalized to the corresponding value of the housekeeping gene (Actb). Data are exhibited as log 2 fold changes of relative expression levels of each group compared to the vehicle. * and $* *$ indicate $p \leq 0.05$ and $p \leq 0.01$. 
A

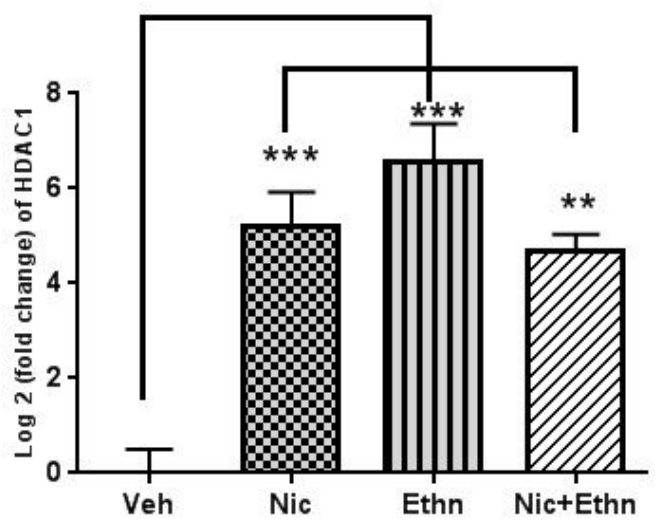

B

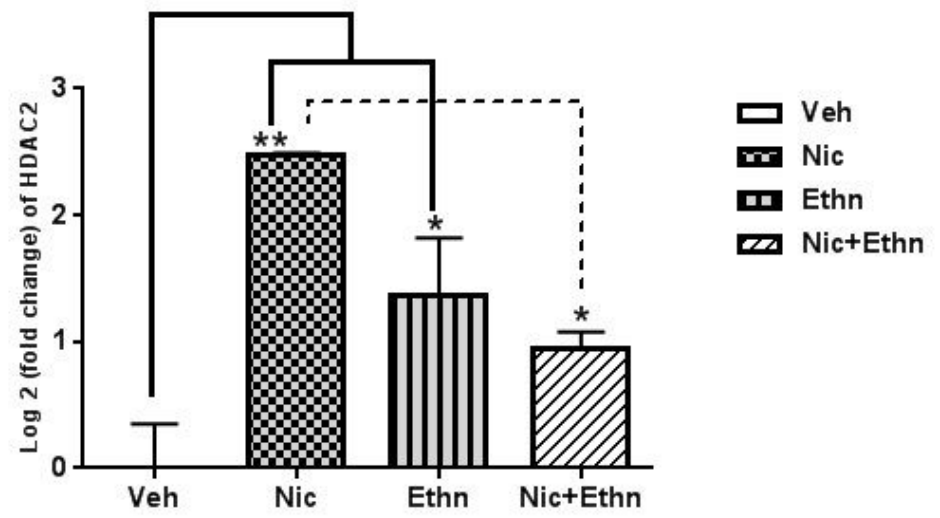

Figure 5

The effect of maternal exposure to nicotine and ethanol, alone and concurrently, on the expression level of enzymes involved in histone deacetylation. Real-time quantitative PCR (RT-qPCR) analysis of histone deacetyltransferase (HDAC) 1 and 2 gene expression in sperm cells of F1 sperm cells from vehicle and exposed animals. Graphs present mean \pm SEM. Data from each gene were normalized to the corresponding value of the housekeeping gene (Actb). Data are exhibited as log 2 fold changes of relative expression levels of each group compared to the vehicle. ${ }^{*}$ ** and $* \star \star$ indicate $p \leq 0.05, p \leq 0.01$ and $p \leq$ 0.001.

\section{Supplementary Files}

This is a list of supplementary files associated with this preprint. Click to download.

- supplementaryinformation.pdf 